\title{
Em busca de um estudo eficiente e autônomo: abordagens na música e a integração através do gerenciamento de projeto
}

In search of an efficient and autonomous study: Approaches in music and the integration through project management

Laís Fernandes dos Santos ${ }^{1}$ Universidade Estadual de Maringá (UEM) laisflauta@gmail.com

Alfeu Rodrigues de Araújo Filho ${ }^{2}$ Universidade Estadual de Maringá (UEM) arafilho@uem.br 


\section{Resumo}

A escassez de tempo (característica da contemporaneidade), a dependência em relação ao professor durante o estudo individual e a generalização dos problemas apontam a necessidade de um estudo eficiente e autônomo que se adéque às particularidades do indivíduo. Através de uma revisão da literatura na área da música, podemos verificar que os trabalhos existentes estão voltados, em sua maioria, para problemas especificos, normalmente práticos e técnico-instrumentais. A partir disso, buscamos ofertar aos músicos um caminho para integrar todos os âmbitos do estudo já tratados pelos pesquisadores: a prática deliberada, a organização, o planejamento, a autorregulação, as estratégias e ferramentas. Considerando a construção de teorias por meio da abstração (DEWEY, 1920), nossa proposta se baseia no gerenciamento de projetos ao traduzir para a música as principais práticas de acordo com o Guia PMBOK® (PMI, 2017). Como se trata de uma pesquisa ainda em desenvolvimento, ajustes serão necessários.

Palavras-chave: Gerenciamento de projeto do estudo. Integração. Eficiência. Autonomia. Performance.

\section{Abstract}

The scarcity of time (characteristic of contemporaneity), the dependence on the teacher during the individual study and the generalization of the problems point to the need for an efficient and autonomous study that suits the individual's particularities. Through a literature review in the area of music, we can verify that the existing works are mostly focused on specific problems, usually practical and technical instrumental. From this, we seek to offer musicians a way to integrate all areas of study already addressed by researchers: deliberate practice, organization, planning, self-regulation, strategies and tools. Considering the construction of theories through abstraction (DEWEY, 1920), our proposal is based on project management by translating the main practices into music according to the PMBOK® Guide (PMI, 2017). This is research in progress, so adjustments will be needed.

Keywords: Study project management. Integration. Efficiency. Autonomy. Performance.

\footnotetext{
1 Possui especialização em Educação Musical pelo Centro Universitário Claretiano (2018), assim como Bacharelado em Música com Habilitação em Flauta Transversal pela Faculdade de Música do Espírito Santo (2017). Atualmente é mestranda em Música pelo Programa de Pós-Graduação em Música - PMU - da Universidade Estadual de Maringá (UEM), bolsista da Coordenação de Aperfeiçoamento de Pessoal de Nível Superior (CAPES) pelo programa Demanda Social e membro do grupo de pesquisa Os Problemas da Interpretação, e tem como foco de pesquisa o estudo musical na preparação para a performance.

2 Natural de São Paulo, formado em Bacharel em Música (1989), Mestrado em Artes (1996) e Doutorado em Música (2011) na área de práticas interpretativas - piano - todos realizados na Universidade Estadual de Campinas (UNICAMP). Em seu mestrado, foi bolsista da FAPESP (Fundação de Amparo à Pesquisa do Estado de São Paulo). Atualmente é professor efetivo de piano da Universidade Estadual de Maringá (UEM), assim como professor credenciado no Programa de Pós-Graduação em Música - PMU - da UEM e membro do grupo de pesquisa Os Problemas da Interpretação. Dentre as ações administrativas na Universidade Estadual de Maringá, exerceu o cargo de Coordenador do Curso de Artes Cênicas no período de 06/2016 a 06/2019 e, atualmente, é chefe adjunto do Departamento de Música e Artes Cênicas (DMC).
} 


\section{Introdução}

A escolha do tema se deve à procura de soluções para problemas relacionados à performance instrumental, como o mau aproveitamento do tempo e do esforço investido na preparação. A escassez de tempo, característica da contemporaneidade, ratifica tal investigação para otimizar o estudo em função do grande volume de conhecimentos necessários, da elaboração de trabalhos, do equilíbrio da vida pessoal, profissional e social, da complexidade da literatura musical, assim como da alta qualidade exigida nas práticas interpretativas. A consequência da má administração poderá acarretar desmotivação, dúvidas e carência de resultados qualitativos inerentes à diversidade de aspectos técnicos e musicais da execução instrumental.

Outro fator a ser considerado é a dependência em relação ao professor, levando à falta de postura reflexiva e crítica do processo de estudo, ações automáticas e desprovidas de significados internos. Neste aspecto, a pesquisa poderá contribuir para qualificar o período de atuação do instrumentista após a aula individual, na busca por soluções para os possíveis conflitos e dúvidas ao longo da semana. Isso pode ser reparado na postura dos recém-formados, em sua grande maioria, desorientados e com inúmeros conflitos quanto ao processo metodológico. Vale frisar que a generalização de problemas técnicos e expressivos, adotados como recursos universais, não promovem a auto-observação e a autoavaliação, ações imprescindíveis para adequar às dificuldades pessoais e evitar o agravamento de problemas.

O objetivo deste artigo é propor um suporte metodológico que promova eficiência e autonomia no gerenciamento da preparação para a performance de obras musicais, sendo destinado, mas não limitado, a músicos em início de carreira profissional (alunos de Graduação em Música ou recém-formados) no meio erudito, por conta das características desse gênero. O primeiro passo é identificar as pesquisas já existentes nessa temática e afins.

\section{Abordagens existentes na preparação para a performance}

Com relação à área da performance musical, Barros (2008) apresenta uma revisão da literatura sobre o planejamento da execução instrumental com análise quantitativa de assuntos e metodologias. As pesquisas foram divididas em três temáticas principais: estratégias de estudo; cognição e memorização; comportamento, organização e tipos de prática. A terceira temática possui o maior volume, com muitas pesquisas embasadas na psicologia e na neurociência. Em seguida, o autor examina criticamente os problemas metodológicos das pesquisas empíricas, as estratégias de estudo pianístico e sua própria experiência como sujeito em um estudo de caso.

Em seu artigo sobre música de câmara, Ray também identifica que, “No Brasil, textos em periódicos e Anais de congressos que discutem música de câmara são geralmente concentrados em discussões de cunho interpretativo, tangenciando aspectos 
musicológicos e/ou analíticos" (RAY, 2019, p. 156). Os próprios temas e formas de abordagem de Barros (2008) e Ray (2019) frisam o enfoque direto na prática musical, como a escolha dos exercícios, formas de distribuição do tempo, qualidade do estudo, estratégias, técnicas etc. Nota-se também que grande parte das pesquisas se fundamentam em áreas como psicologia, cognição, neurociência e comportamento.

A revisão de literatura para o presente trabalho foi realizada a partir da seleção de publicações disponíveis nos sítios eletrônicos do banco de teses e dissertações da Capes, inserindo as palavras-chave organização do estudo e preparação da performance. Na continuidade, foram examinados os principais periódicos brasileiros digitais e gratuitos da área de música, considerando os volumes de 2016 a outubro de 2020: Per Musi, Opus, Hodie, Vortex e Orfeu. A análise da aproximação com os temas - estudo e preparação para performance - seguiu três etapas de eliminação: título, resumo e texto completo.

A maior parte dos textos trata estritamente da música e do fazer musical. Na sequência, apresentamos as porcentagens em relação às pesquisas consideradas no presente artigo. Estudos das áreas de teoria musical e composição não foram contabilizados. Dos 60 trabalhos, temos: Análise (11,6\%), Interpretação (18,3\%), Aspectos técnicos (11,6\%) e Improvisação (10\%), representando 51,5\% dos trabalhos. Ou seja, mais da metade da literatura encontrada trata de obras, compositores, instrumentos e estilos específicos.

Nessa mesma direção, os materiais didáticos, também conhecidos como métodos, normalmente apresentam exercícios, ensinamentos e conselhos para melhorar a técnica instrumental. O artigo de Farias Bujes (2017) tem como principal objetivo a análise do método Milanov para violino, focado na autonomia do aluno, indicando o papel do educador. $O$ autor também aponta os principais temas dessas literaturas, voltados para a técnica e para a atuação do professor, e pesquisas sobre a eficácia das metodologias. Em conformidade, Vetromilla e Gabriel (2019) comentam os exercícios da prática diária de um músico renomado.

Outro tópico comum são as estratégias, isto é, as formas utilizadas para alcançar determinados objetivos. Cara Jara (2019) investigou como os alunos trabalham uma peça musical nova e avaliam seu progresso, indicando ao professor uma forma de avaliação. Em outro caminho, Drayton (2013) reflete acerca do uso de modelos (em áudio ou escrito) para o estudo, visando à eficiência. No entanto, a perspectiva principal na área da performance é a de apontar estratégias de memorização ou desenvolvimento técnico para uma peça, situação ou instrumento, como nos seguintes trabalhos: "Memorização, Percepção Musical e Cognição - oito questionamentos do dia-a-dia" (CAREGNATO, 2017), "Primeira Sonata-fantasia, désespérance, para violino e piano de Heitor Villa-Lobos: estratégias de estudo para violinista" (P. A. J. GARCIA, 2015), "Audições orquestrais para flauta no Brasil: um estudo sobre estratégias de preparação" (J. M. B. RODRIGUES, 2015), "Aprendizagem e transferência de habilidades motoras no ensino de piano funcional em grupo" (M. A. COSTA, 2018).

O próximo tema que se destaca é a prática deliberada, que 
[...] consiste numa atividade altamente estruturada com o estabelecimento de metas, identificação e resolução de erros, energia, atenção e concentração para praticar por períodos regulares, investimentos em recursos externos e desenvolvimento de tarefas específicas com o objetivo de superar os limites atingidos e melhorar o atual nível de desempenho. (ERICSSON; KRAMPE; TESCH-RÖMER, 1993 apud MANTOVANI; R. A. T. SANTOS, 2018, p. 27).

Esse conceito foi apresentado por Mantovani e R. A. T. Santos (2018), no qual as autoras fazem uma análise fenomenológica da prática. Algumas investigações adotam um caminho semelhante, discutindo a importância e os efeitos do estudo estruturado, como os de J. Z. Oliveira (2019) e Ericsson, Krampe e Tesch-romer (1993). Mais uma vez o próprio termo está centrado na execução instrumental, pois, mesmo que discuta a sua sistematização, não há um cuidado com o contexto geral em que se insere.

Junto com a prática deliberada, diversos autores trazem a autorregulação, um conceito da psicologia relativo ao controle dos próprios comportamentos e pensamentos (VELOSO; R. C. ARAÚJO, 2019; QUINTERIO, 2017). Cremaschi (2012) e Piccoli (2016) o utilizam para elaborar uma forma de autoavaliação para acompanhar o desenvolvimento e o engajamento pessoal. É um conceito que, diferentemente dos demais, não se refere à prática propriamente, mas ao gerenciamento pessoal e de ações:

A autorregulação - constructo psicológico [...] - é caracterizada pela ênfase nos fatores comportamentais, motivacionais, cognitivos e metacognitivos dos empreendimentos humanos mobilizados em diferentes contextos. No âmbito educacional, a "autorregulação da aprendizagem" diz respeito a um conjunto de mecanismos que as pessoas usam para dirigir o próprio desenvolvimento, a partir do delineamento de objetivos e diretrizes de estudo, atentando para o gerenciamento do próprio progresso e utilizando estratégias de planejamento, monitoramento e avaliação dos pensamentos, sentimentos e ações, visando à realização de mudanças autodirecionadas. $O$ estudo autorregulado inclui, dentre outros aspectos, a planificação das tarefas, o estabelecimento de metas, o delineamento de estratégias, o automonitoramento, o julgamento pessoal dos desempenhos e fatores motivacionais, como as "crenças de autoeficácia", compreendidas como a percepção pessoal em relação à própria inteligência, as habilidades, os conhecimentos e os recursos que se dispõe para a realização de determinada tarefa. (SCHUNK, 2015 apud VELOSO; R. C. ARAÚJO, 2019, p. 134).

Apesar de estar em outra direção, isto é, o gerenciamento conectado aos múltiplos contextos, também não se compromete com o todo do estudo, mas com o indivíduo; dessa forma, a regulação do treino acontece por meio do controle do instrumentista sobre si mesmo.

Em complemento à autorregulação e próxima da prática deliberada, está a organização, apresentada em alguns textos na forma de modelos de rotina diária, como o de Kimachi (2014), enquanto outros apontam parâmetros para determinar metas e sua importância: Chaffin e Imreh (2001), Mezzadri (2017) e Carvalho (2016). A maior parte dos pesquisadores equiparam a organização e o planejamento, resumidos na identificação de problemas e estabelecimento de objetivos, sendo aplicados e exemplificados através 
de obras, como em Barros, Carvalho e Borges (2017), R. Alves, Noda e Cesetti (2019) e Pontes (2017).

A organização também é habitualmente compreendida em estabelecer metas, escolher e sequenciar atividades, conforme pode-se perceber nos textos de Hallam, Creech e Varvarigou (2018) e Hallam et al. (2012). Aderindo a esse sentido, Póvoas (2017) desenvolve um sistema voltado para a coordenação motora que "visa a eficiência do treinamento técnico-musical e sua otimização por meio da distribuição e variabilidade da prática" (PÓVOAS, 2017, p. 187). Ele possui três etapas que frisam o conceito estrito à execução instrumental: reconhecimento do material, divisão da peça em trechos e sequenciamento desses.

A partir da revisão apresentada, observa-se que, em geral, os autores buscam soluções para problemas pontuais. É importante ressaltar que os autores de referência nas áreas da prática deliberada, autorregulação e organização são compartilhados entre os trabalhos selecionados, portanto é plausível considerar que a abordagem seja semelhante em boa parte da literatura.

Quanto aos dois aspectos almejados, eficiência e autonomia, o primeiro é um dos objetivos na maioria das investigações, enquanto o segundo está presente em algumas, porém normalmente se referem à atuação do educador para promovê-la, não nas metodologias usadas pelos alunos. Exemplos disso são os artigos de Fagundes e Ribeiro (2016), sobre a motivação autônoma, e de Glaser (2018), que defende a autonomia do músico nos seus estudos individuais, embasando em Dewey a necessidade de independência, a continuidade do aprendizado e a influência dos fatores socioemocionais na performance, frisando a importância do papel do professor de promover tais recursos por meio de motivação e receptividade.

Dessa forma, verificamos uma lacuna quanto ao gerenciamento que busque estruturar e integrar tais âmbitos específicos, como a prática deliberada, a organização, o planejamento, a autorregulação, as estratégias e ferramentas, assim como conduza a adequação de cada etapa às particularidades do músico, da obra e do contexto em que o estudo se insere. Na busca por uma resposta a essa carência, apresentamos, a seguir, a construção de um possível caminho por meio do diálogo com outros campos.

\section{Metodologia}

Por conta da centralização na busca pela solução de um problema prático da área da performance musical, a corrente filosófica que se mostra mais coerente é a pragmática. Ela se caracteriza pela concepção da ideia, da razão, como ferramenta que orienta as ações para a resolução de problemas práticos. Apesar de os pragmáticos serem acusados de utilitarismo em alguns momentos,

[...] o que a teoria pragmática tem em mente é precisamente o fato de que todos os assuntos da vida que precisam de regulação - todos os valores de todos os tipos - dependem da utilização de significados. A ação não deve ser limitada a 
nada menos do que a saída de ideias, do que a execução, árdua ou fácil, de significados. (DEWEY, 1910b, p. 109, grifo do autor, tradução nossa). ${ }^{3}$

O autor adotado, especialmente por conta da ênfase na autonomia do indivíduo, é John Dewey (1859-1952): "Não há, eu penso, ponto na filosofia da educação progressista que é mais preciso que sua ênfase na importância da participação do aprendiz na formação dos propósitos que direcionam suas atividades no processo de aprendizagem"4 (DEWEY, 1938, p. 67, tradução nossa).

Os termos utilizados por ele são liberdade e autoatividade. ${ }^{5}$ Segundo Dewey, "liberdade significa essencialmente a parte desempenhada pelo pensamento - que é pessoal - na aprendizagem: - isso significa iniciativa intelectual, independência na observação, invenção judiciosa, previsão de consequências e engenhosidade de adaptação a elas"6 (1916, l. 4985, tradução nossa). Tal liberdade é considerada dentro do ambiente da própria aula, incluindo a participação do docente. Por conta disso, foi escolhida, para o presente trabalho, a palavra autonomia, ${ }^{7}$ pois está centrada nos momentos de ausência do professor, nos quais o músico necessita gerir suas ações para obter a própria liberdade.

Conforme exposto, são escassos os estudos sobre gerenciamento, especialmente no âmbito da performance. No empenho em encontrar fundamentos para a elaboração de metodologias, nasceu a ideia de utilizar conhecimentos de campos especializados em gestão, organização e planejamento, no caso, o gerenciamento de projetos. Esse se configura como uma profissão do campo administrativo, cujo objetivo é, de maneira geral, garantir que determinadas atividades atinjam os resultados almejados com eficiência (PMI, 2017).

A construção de teorias pode ser feita por meio da abstração: "Observadas funcionalmente, não estruturalmente e estaticamente, abstração significa que algo foi libertado de uma experiência para transferência a outra"8 (DEWEY, 1920, p. 150, tradução nossa). Dessa forma, um aspecto de uma experiência é desprendido de seu contexto (gerenciamento de projetos empresariais) para sugerir novas respostas aos problemas previstos (estudo musical).

Integrantes da abstração, a indução é a descoberta de princípio vinculativo, enquanto a dedução é o teste com base na capacidade de interpretar detalhes da ex-

3 Original: "[...] what the pragmatic theory has in mind is precisely the fact that all theaffairs of life which need regulation - all values of all types - depend upon utilizations of meanings. Actions is not to be limited to anything less than the carrying out of ideas, than executation, whether strenuous or easeful, of meanings".

4 Original: "There is, I think, no point in the philosophy of progressive education which is sounder than its emphasis upon the importance of the participation of the learner in the formation of the purposes which direct his activities in the learning process".

5 Tradução nossa. Termos originais: freedom e self-activity.

6 Original: "Freedom means essentially the part played by thinking - which is personal - in learning: - it means intelectual initiative, Independence in observation, judicious invention, foresight of consequences, and ingenuity of adaptation to them".

7 Aptidão ou competência para gerir sua própria vida, valendo-se de seus próprios meios, vontades e/ou princípios (AUTONOMIA, 2020).

8 Original: "Looked at funcionally, not structurally and statically, abstraction means that something has been released from one experience for transfer to another". 
periência (DEWEY, 1910a). Dessa forma, o processo indutivo aqui é a visão do estudo musical como um projeto a ser gerenciado, enquanto o dedutivo consiste na proposta de aplicação das práticas empresariais de gerenciamento ao estudo.

Rooij (2009) diz que há indicações de que o Guia PMBOK®, principal referência das práticas empresariais para o presente trabalho, possa oferecer estrutura para projetos de várias disciplinas, faz menção ao estudo da aplicação dessas práticas em classes de psicologia (CHIOCCHIO, 2007 apud ROOIJ, 2009) e à visão das práticas de gerenciamento de projeto como genéricas e aplicáveis a várias outras, segundo Crowford e Pollack (2007 apud ROOIJ, 2009). Os estudos desses autores evidenciam a afirmação do Guia PMBOK® (PMI, 2017) de que as práticas nele contidas são adequadas à maioria dos projetos, levando a perceber uma pertinência na proposta de adaptação para o ramo da música. Esse material também permite e requer o desenvolvimento e a inclusão de ferramentas e técnicas personalizadas (ZWIKAEL, 2009), específicas de uma determinada alçada para propiciar o amplo emprego.

Nesses processos de abstração, a inteligência deve ser utilizada como método para distinguir e selecionar os elementos da realidade que são úteis, que sejam meios para alcançar os fins necessários (DEWEY, 1920), como a escolha das práticas e técnicas de gerenciamento aplicáveis à música. Segundo o filósofo, "para agir com sucesso, devemos agir após a seleção consciente - depois da discriminação de meios e fins"9 (DEWEY, 1910b, p. 42, tradução nossa).

Em continuação, Dewey diz que "os processos dedutivos definem, delimitam, purificam e ordenam as concepções pelas quais essa operação enriquecedora e diretiva é realizada, mas eles não podem, ainda que perfeitos, garantir o resultado"10 (DEWEY, 1920, p. 151, tradução nossa). Isto é, não é possível assegurar que algo extraído do concreto será frutífero em um caso individual, pois já se diferem em suas naturezas (DEWEY, 1920). Dentre os principais questionamentos sobre a eficácia da presente proposta, estão:

- A eficiência no estudo se equipara à eficiência dos projetos empresariais?

- O atendimento às exigências das partes interessadas, das normas e da situação do projeto equivale ao atendimento das necessidades e particularidades de um indivíduo?

- São similares a autonomia prevista do gerente e a autonomia do performer no sentido de independência do professor?

Dentro de algumas instituições, há o Gerenciamento Organizacional de Projeto (Organizational Project Management - OPM). Seu intuito é fornecer um suporte aos gerentes para o alinhamento do projeto com os propósitos e as estratégias da empresa (PMI, 2018). Na música, o gerente é o próprio instrumentista, enquanto o suporte organizacional pode ser o professor ao estabelecer os parâmetros da performance, 0 repertório e orientar o estudo.

9 Original: "[...] in order to act successfully, we must act after conscious selection - after discrimination of means and ends".

10 Original: "Deductive processes define, delimit, purify and set in order the conceptions through which this enriching and directive operation is carried on, but they cannot, however perfect, guarantee the outcome". 
Um dos domínios do OPM é a estratégia, ou seja, "um plano de alto nível projetado para alcançar os principais objetivos usando recursos internos e externos da organização de forma eficiente e eficaz" (PMI, 2018, p. 3). Seguindo tal caminho, propomos um plano de estudo geral a partir de pesquisas nos campos musical e administrativo, considerando que tal estruturação poderá oferecer aos músicos dois principais anseios: eficiência e autonomia.

A estrutura responsável pelo OPM tem entre suas funções principais desenvolver modelos, metodologias, procedimentos e documentos para auxiliar os gerentes (PMI, 2018). Considerando que o instrumentista será o gerente de seu próprio estudo, nossa proposta pode ser considerada uma metodologia de gerenciamento organizacional: “[...] grupos de processos e práticas de gerenciamento de projetos inter-relacionados [...] procuram aumentar a probabilidade do sucesso do projeto e melhorar a eficácia e eficiência do projeto" (PMI, 2018, p. 25), isto é, um conjunto de práticas de organização para qualificar, direcionar e estruturar tal ação por meio de recursos diversos com uma leitura interdisciplinar, selecionando elementos administrativos empresariais que se aplicam à música.

\section{Gerenciamento de projetos}

Para a construção dessa proposta, partimos da comparação entre estudo - energia dedicada ao conhecimento - e projeto: “[...] um esforço temporário empreendido para criar um produto, serviço ou resultado único" (PMI, 2017, p. 4). Nesse contexto, adotamos como base o Um Guia do Conjunto de Conhecimentos de Gerenciamento de Projetos - Guia PMBOK®, sexta edição, que contém o padrão e guia globalmente reconhecidos para a profissão de gerenciamento de projetos (PMI, 2017), organizado pelo Project Management Institute (PMI) e elaborado voluntariamente por profissionais da área, liderados nessa edição por Cyndi Snyder Dionisio (presidente) e David A. Hillson (vice-presidente).

A escolha do Guia PMBOK®, dentre outros existentes, se deu pela sua relevância: foi aceito como padrão de gerenciamento pelo American National Standard Institute (ANSI), é referência subjacente da International Organization for Standardization (ISO), assim como utilizado por empresas de grande porte (Nasa e Petrobras). Sua intenção é fornecer um léxico comum, criar uma estrutura e profissionalizar o gerenciamento de projetos (HODGSON; CICMIL, 2006).

O intuito desse material é auxiliar organizações e gerentes de projetos a criarem "metodologias, políticas, procedimentos, regras, ferramentas e técnicas e fases do ciclo de vida necessários para a prática do gerenciamento" (PMI, 2017, p. 2). Dessa maneira, fica a cargo do gerente avaliar como será a aplicação para cada projeto, atento às necessidades e particularidades da situação. Na tradução para a música, isso se reflete na efetivação da autonomia ao ofertar aos instrumentistas práticas para auxiliar a construção de suas próprias formas de organização do estudo, intencionando promover uma ação dinâmica, ativa e reflexiva em vez de um esquema pronto. 
Na busca constante pela melhor interpretação e execução possível das obras musicais, são fundamentais a mutação e o dinamismo do estudo, o qual deve acompanhar os avanços e promovê-los cada vez mais, sempre se ajustando às novas realidades que surgem ao longo do processo. Em consonância, fazem parte das práticas de gerenciamento no campo administrativo a reformulação e a revisão ao longo de todo o projeto, isto é, além do planejamento prévio, inclui também modificações que ocorrem durante a execução das tarefas e atividades: "[...] o processo Realizar o Controle Integrado de Mudanças é conduzido do início ao término do projeto e é de responsabilidade do gerente de projeto" (PMI, 2017, p. 115). O próprio Guia PMBOK® passa por uma revisão a cada quatro ou cinco anos com a finalidade de corrigir e adequar às tendências mais recentes da área e da sociedade.

Outra característica que se destaca nessa profissão é o enfoque fundamental na integração. A função principal do gerente de projeto é garantir que todos os aspectos estejam conectados, enquanto os âmbitos específicos são delegados a outros gerentes. Da mesma maneira, a proposta desta pesquisa é promover a integração das múltiplas dimensões do estudo, algumas já citadas ao longo da revisão de literatura.

Atualmente, empresas de grande porte e produtores culturais usam processos estruturados para gerenciar projetos por meio da aplicação de conhecimentos, habilidades e ferramentas. Ao atenderem aos requisitos definidos previamente, conseguem alcançar as metas estipuladas. No mercado de trabalho, a função de gerente de projeto está em otimizar os esforços, recursos, tempo, além de reduzir os riscos para atingir os resultados almejados. Para isso, uma metodologia organizacional, já mencionada anteriormente, pode contribuir e facilitar a estruturação baseada no ajuste de um modelo fornecido por uma instituição ou por um administrador.

Enfatizando a importância de o gerente adequar as orientações a cada situação específica, o PMI afirma que as metodologias de gerenciamento organizacional de projetos devem, dentre outros fatores,

Fornecer orientação para ajustar e aplicar a metodologia aos contextos específicos do projeto [...]. Todas as metodologias de OPM requerem ajuste como parte do trabalho de desenvolvimento através do qual elas são estabelecidas e como parte do trabalho contínuo através do qual elas são mantidas. Adequar se refere ao trabalho de desenvolvimento através do qual metodologias de OPM são aprimoradas para melhor se adequarem ao cenário, cultura e circunstância organizacionais e para melhor fornecer os resultados esperados. (PMI, 2018, p. 28).

No estudo musical, isso se expressa no papel do músico de moldar a proposta aqui apresentada para as suas particularidades, ou seja, o ajuste por meio da observação e do registro das características e necessidades do músico, da obra e da performance para fornecer os melhores resultados possiveis.

Quanto às práticas contidas no Guia PMBOK®, Rooij (2009) buscou responder a alguns questionamentos sobre sua efetividade por meio da comparação do uso ou não dessas técnicas como suporte para a aprendizagem virtual baseada em projeto por grupos de estudantes de graduação em tecnologia. A conclusão foi positiva: ambos os grupos alcançaram o resultado almejado, mas o gerenciamento deixou a comunicação 
mais concisa e aumentou o envolvimento no grupo que o utilizou, ou seja, aumentou a eficiência e a autonomia no processo. No estudo musical, seria equivalente a dois instrumentistas terem performances com a mesma qualidade, porém, gerenciando, ocorreu a redução do tempo de estudo e o aumento da autonomia, possibilitando realizar boa parte das tarefas de maneira independente, tendo o professor como suporte nos momentos de dúvidas e dificuldades.

Hodgson e Cicmil (2006), pesquisadores sobre o gerenciamento de projetos, afirmam que, para construir o conceito de projeto, é necessário naturalizá-lo em uma base universal e difundida e criticam essa tentativa de estabelecer padrões: uma descoberta de leis universais preexistentes e exteriores às quais a sociedade é conformada posteriormente; um ideal platônico que impõe um sistema de classificação. De fato, para elaborar uma metodologia para o contexto da música, consideramos alguns fatores como universais pela sua frequência dentro do contexto social em que nós, autores, estamos inseridos. Porém, não procuramos um padrão no sentido de molde, algo a ser imitado ou utilizado como parâmetro de comparação, e sim como um modelo para auxílio, um ponto de partida. Por exemplo: um fator que adotamos como universal é a utilização de partitura por estar voltada à música erudita, porém, se for colocado rigidamente, outros gêneros musicais que não utilizam notação escrita não poderiam utilizar a metodologia proposta.

Com base nos padrões estabelecidos, a principal divisão do Guia PMBOK® é por áreas de conhecimento, das quais dez estão contempladas no guia. São elas:

- Integração: unifica os processos de todas as áreas;

- Escopo: descreve o trabalho a ser feito e assegura a abrangência de tudo que é necessário;

- Cronograma: organiza as atividades para garantir o término pontual;

- Custos: controla o orçamento, incluindo o valor da hora de trabalho empreendida;

- Qualidade: define as características do resultado almejado e as condições de qualidade para alcançá-lo;

- Recursos: materiais, equipe e instalações necessárias (como partitura, estante, metrônomo, afinador, sala para estudo, gravador de áudio e de vídeo);

- Comunicações: contato com envolvidos (seus e-mails e números de telefone);

- Riscos: problemas que podem ocorrer (erros em trechos difíceis, partitura cair, esquecer a música tocando sem partitura, som falhar, ambiente muito quente ou frio, iluminação ruim etc.);

- Aquisições: o que precisa comprar ou alugar;

- Partes interessadas: quem está envolvido na coordenação do projeto.

De acordo com Zwikael (2009), é importante selecionar e priorizar as áreas do conhecimento que mais afetam o sucesso do projeto, conforme o tempo disponível. 0 foco de sua pesquisa foi na etapa do planejamento, que tem como propósitos primários estabelecer o que e quando deve ser feito e quais recursos usar (ZWIKAEL, 2009). Em consonância, diversos trabalhos desse e de outros autores apontaram que, na análise 
da relação entre a dedicação ao planejamento de cada área e o sucesso do projeto, o resultado foi que as três mais influentes são, respectivamente: tempo, ${ }^{11}$ risco e escopo (ZWIKAEL, 2009). Essa constatação se deve ao fato de que pontualidade, prevenção de problemas e cumprimento de exigências são os aspectos mais comuns para determinar o sucesso de projetos.

Considerando que a área integração é a conexão entre as demais, podemos inserir nela as informações essenciais das outras e utilizá-la como resumo de todos os processos. A partir disso, as áreas mencionadas no Guia PMBOK® podem ser abordadas nela, separando apenas as áreas mais relevantes para atender às necessidades do projeto. Para a presente pesquisa, vamos nos aprofundar, além da própria integração, nas primeira e terceira áreas mencionadas por Zwikael (2009) - tempo (cronograma) e escopo -, pois são responsáveis pelo cumprimento de todas as exigências do resultado final e pela pontualidade. Ainda segundo esse autor, os riscos são tratados em grande parte informalmente, embutidos em outros processos, como na estimativa das durações das atividades, em que é considerada uma margem de erro, reforçando a possibilidade de inserção na integração.

\section{Fluxo de processos}

Em cada projeto são realizados diversos processos de gerenciamento, que são "séries de atividades de gerenciamento de projeto" (PMI, 2017, p. 22), traduzidos na música como o conjunto de procedimentos inseridos em cada etapa da organização do estudo, não incluindo o ato de estudar em si, que é constituído das atividades definidas através dos processos de gerenciamento. Eles são agrupados de acordo com a função e o momento em que ocorrem, sendo citados cinco grupos no Guia PMBOK®: iniciação, planejamento, execução, monitoramento e controle e encerramento (PMI, 2017).

Além disso, são classificados também pelas áreas de conhecimento às quais pertencem: "[...] uma área identificada de gerenciamento de projetos definida por seus requisitos de conhecimentos e descrita em termos dos processos que a compõem: suas práticas, entradas, saídas, ferramentas e técnicas" (PMI, 2017, p. 700). Ou seja, são definidas pelo assunto pelo qual seus processos são responsáveis na organização do estudo. Por exemplo: o processo sequenciar as atividades tem como função ordenar previamente as ações, portanto é considerado como parte do grupo de planejamento e da área cronograma. Vargas (2001), baseado na versão do Guia PMBOK® vigente na época, portanto mais antiga, ilustrou em um círculo externo os grupos de processos e em um círculo interno as áreas de conhecimento, conforme a imagem a seguir: ${ }^{12}$

11 Na nova versão do Guia PMBOK® ${ }^{\circledR}$ essa área passou a se chamar cronograma.

12 Os grupos de processos e as áreas de conhecimento atualizados e em português já foram mencionados. O alinhamento dos círculos não é relevante. 


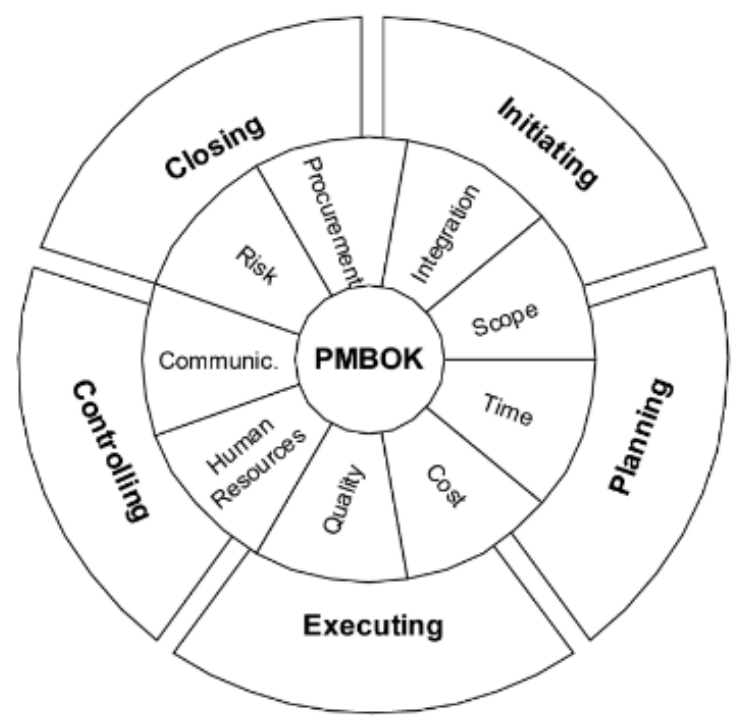

A segmentação pelas categorias de processos se destaca por apresentar uma organização lógica que auxilia a compreender a cronologia do gerenciamento (VARGAS, 2001). A partir disso, Vargas (2001) elaborou um fluxo de processos para apresentar visualmente o funcionamento estruturado do Guia PMBOK®, atualizado em 2017. Apesar de seguir tal ordem cronológica, o fluxo não deve ser cumprido de forma rígida e linear, pois os processos se influenciam mutuamente (PMBOK®..., 2017). Por conta das escolhas já esclarecidas, somente os processos das áreas escopo e cronograma serão explicados, e os processos da integração serão considerados como o âmbito geral.

A seguir encontra-se o fluxo de Vargas (PMBOK®..., 2017) (Fig. 2). Podemos identificar que o centro de todos os grupos é o gerenciamento da integração para coordenar as demais áreas, reforçando a importância dessa área de conhecimento. Logo após, apresentamos nossa tradução para o campo da música (Fig. 3). 


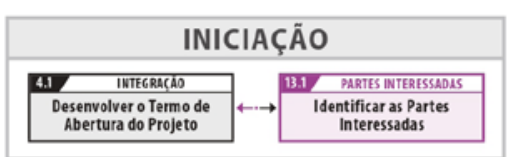

\section{FLUXO DE PROCESSOS DO RICARDO PMBOK $^{\oplus}$ GUIDE $^{\circ}$ EDIÇÃO VA RGAS}

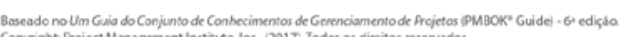
PLANEJAMENTO
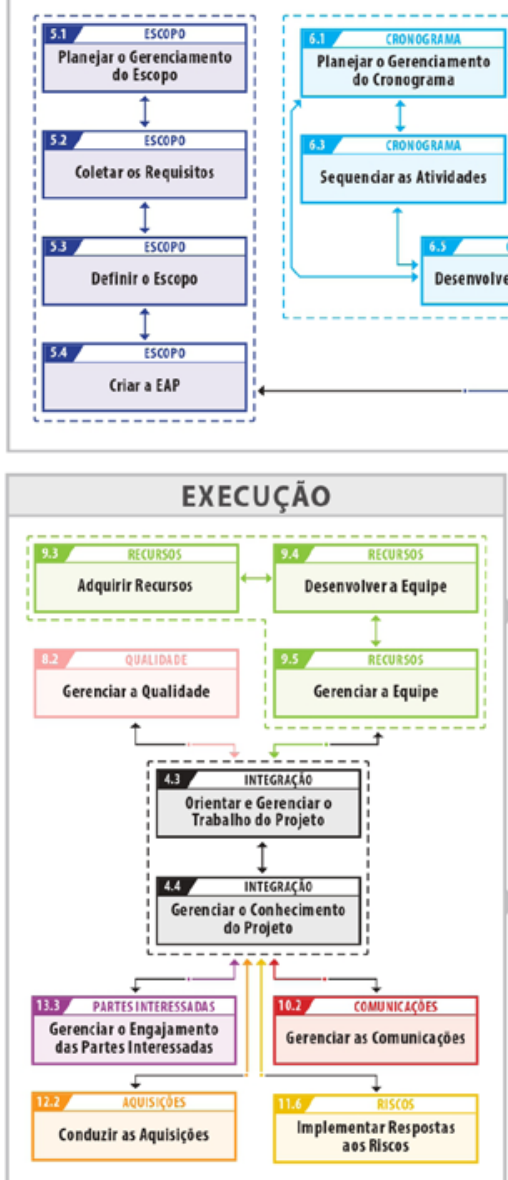

\section{ENCERRAMENTO}

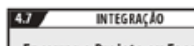

Encerrar o Projeto ou Fase
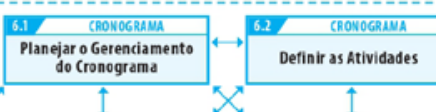
Sequendar as Atividades
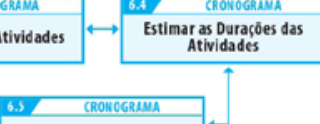

Desenvolver o Cronograma
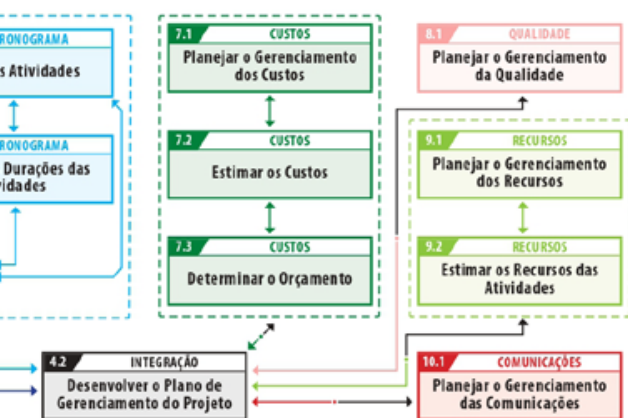

42 INTEGRacho
Desenvolver o Plano de
Gerenciamento do Projeto
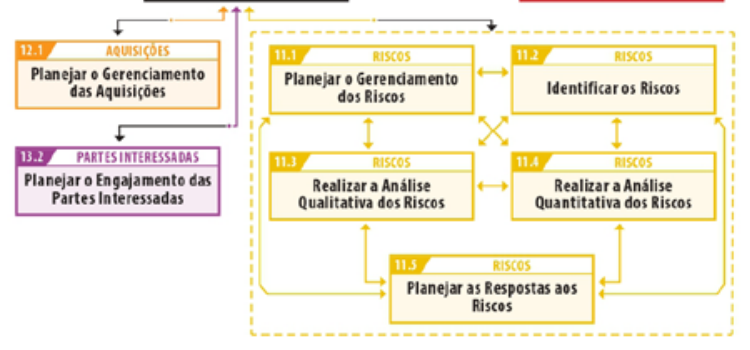

Partes Interessadas

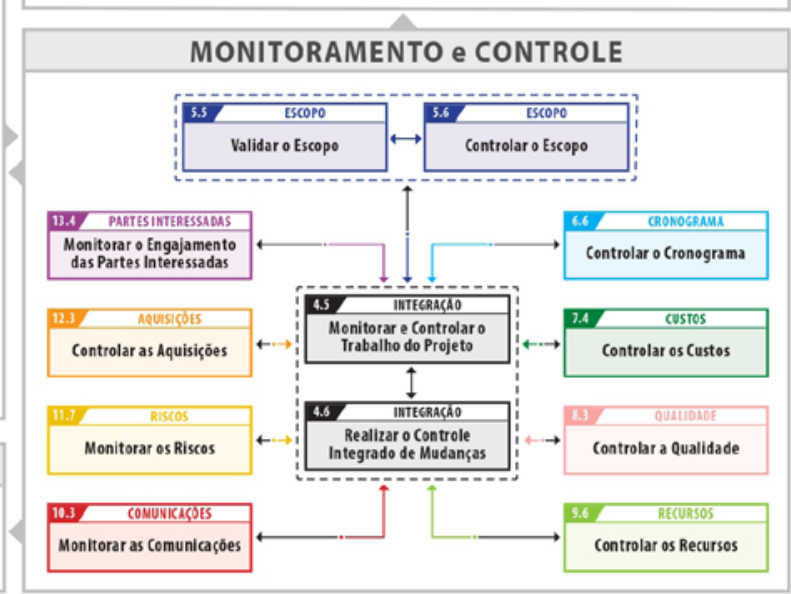

PMBOK॰ GUIDE 6. EDIÇÃO - 49 PROCESSOS GERENCIAMENTO DE PROJETOS

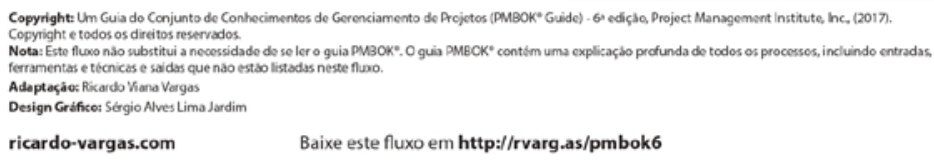

Torne-se um membro do Project Management Institute (PMI) e faça o download do $\mathrm{PMBOK}^{*}$ Guide e todos os outros padrōes no site:

ricardo-vargas.com

Baixe este fluxo em http://rvarg.as/pmbok6

Fig. 2: Fluxo de processos do Guia PMBOK ${ }^{\circledR}$, $6^{\text {a }}$ edição. Fonte: Vargas (2017). 


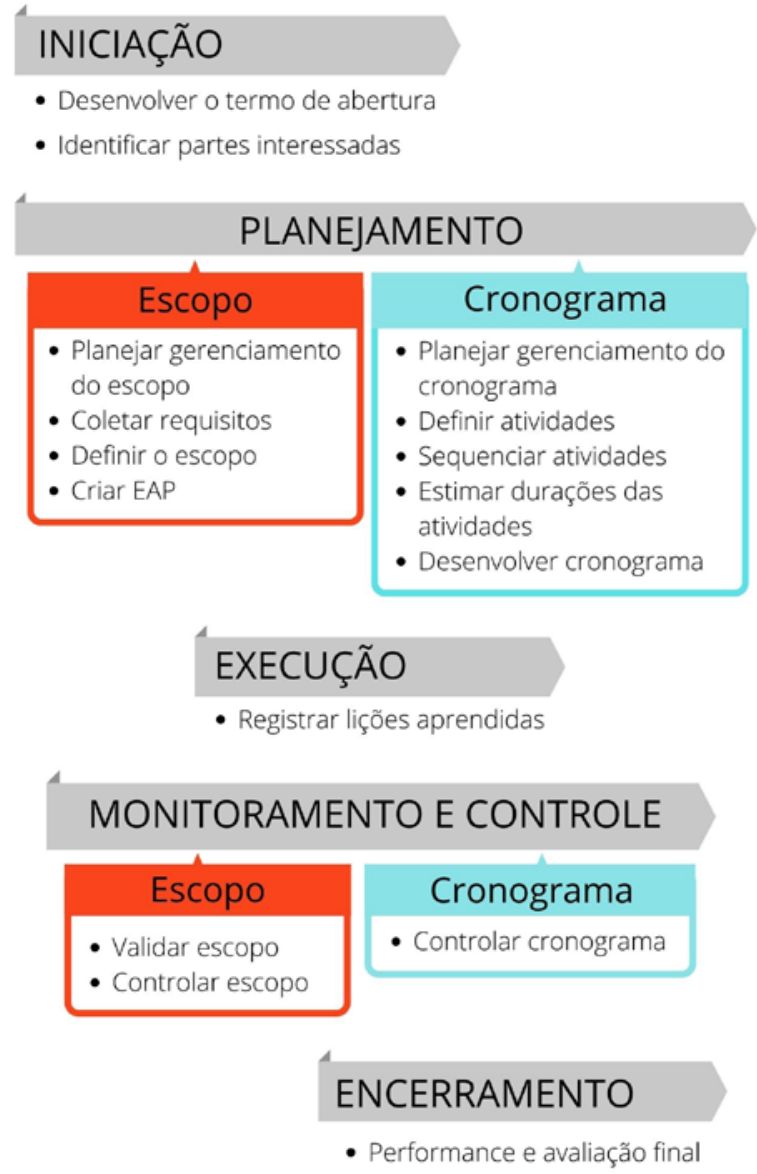

Fig. 3: Fluxo de processos de gerenciamento do estudo musical. Fonte: Elaborado pelos autores.

\section{Iniciação}

Este é o momento em que a ideia se delineia e que as informações gerais são definidas. O primeiro processo, inserido na integração, é desenvolver o termo de abertura: "[...] formalmente autoriza a existência de um projeto e fornece ao gerente do projeto a autoridade necessária para aplicar recursos organizacionais às atividades do projeto" (PMI, 2017, p. 75). Configura-se em registrar os dados gerais do estudo e da performance, como: objetivos, requisitos da obra, datas e locais importantes, repertório, duração, formação instrumental e características almejadas na execução. Junto a esse último, devem ser definidos os requisitos de sucesso, pois

É essencial documentar claramente os objetivos do projeto e selecionar objetivos que sejam mensuráveis. [...] Três importantes questionamentos [...]: O que se considera sucesso neste projeto? Como será medido o sucesso? Quais fatores podem afetar o sucesso? (PMI, 2017, p. 34). 
Sucesso pode ser entendido como a definição do que é considerado uma performance de excelência, como será verificada e fatores que a afetam. Normalmente é determinado pela realização dos objetivos, aspectos técnicos e expressivos, qualidade almejada, satisfação dos envolvidos e cumprimento dos prazos.

A seguir devem ser identificadas as partes interessadas, correspondentes às pessoas ou instituições envolvidas na coordenação do projeto, como patrocinadores, professores, músicos, responsável pelo local e membros da banca avaliadora.

\section{Planejamento}

Nesse grupo é construído, na integração, o plano de gerenciamento, composto pelos planos de gerenciamento de cada área de conhecimento, apresentando seus critérios específicos com o objetivo de alcançar o resultado almejado descrito anteriormente no termo de abertura, como regras de um jogo. A primeira área é escopo, o qual declara as entregas. "Uma entrega é definida como qualquer produto, resultado ou capacidade único e verificável que deve ser produzido para concluir um processo, fase ou projeto " (PMI, 2017, p. 4) e cumprir os objetivos, que, na performance, se refere aos itens ou aspectos presentes na execução instrumental ou utilizados como meio para as práticas interpretativas. Por meio dos seguintes processos se define o que deve ser estudado:

- Planejar o gerenciamento do escopo: determinação da referência a partir da qual os itens de estudo serão definidos, como os parâmetros sonoros, um material didático do instrumento ou os critérios de avaliação previstos no edital de um concurso;

- Coletar requisitos: necessidades e exigências para a performance, ou seja, o que é imprescindível para o sucesso da performance. Por exemplo: as condições obrigatórias descritas nas normas de um edital, demanda de técnicas instrumentais da obra, andamento exigido ou o tempo máximo para uma gravação. É importante identificar a conexão entre os requisitos, suas origens e os objetivos do estudo e da performance;

- Definir o escopo: descrição detalhada do que estudar, feita através da tradução das características da performance em aspectos a serem trabalhados e fatores necessários para alcançá-los;

- Criar Estrutura Analítica de Projeto (EAP): ferramenta de representação visual e decomposição do trabalho a ser feito, partindo do âmbito geral em direção aos detalhes. Inclui também a descrição de cada entrega.

A próxima área é Cronograma. Seu objetivo é alcançar o término pontual do estudo, por isso contém dados de quando e como deve ser realizada cada tarefa. Seus processos são:

- Planejar o gerenciamento do cronograma: informa o que fazer em caso de atraso, de aumento ou diminuição do tempo, como as atividades vão ser escolhidas e ordenadas;

- Definir atividades: escolher exercícios e técnicas que serão utilizados para atingir cada entrega determinada no escopo; 
- Sequenciar atividades: converter a lista em um diagrama com sequência lógica eficiente, considerando que todas as atividades, exceto a primeira e a última, devem ser conectadas a pelo menos uma predecessora e uma sucessora, representando um processo contínuo que culmina no resultado final (PMI, 2017), a performance. Isso evita o esquecimento de atividades e a interrupção de uma etapa do estudo para realizar outra que deveria ter sido executada antes;

- Estimar durações: prever a quantidade de tempo para realizar cada atividade;

- Desenvolver cronograma: dispor graficamente as informações anteriores.

\section{Execução}

Esse é o momento da realização do estudo. Entretanto, no cenário empresarial, muitas vezes o gerente de projeto não é responsável por executar as atividades, por isso os processos centrais de integração são orientar e gerenciar o trabalho do projeto e gerenciar o conhecimento do projeto. De forma simplificada, o primeiro diz respeito ao papel do gerente de orientar a equipe a partir da visão geral, enquanto o segundo está centrado no registro das lições aprendidas: "[...] dificuldades, problemas, riscos e oportunidades percebidas, ou outro conteúdo conforme apropriado" (PMI, 2017, p. 104).

Para o estudo individual - portanto sem equipe - , apenas o segundo processo se mostra pertinente. Na música ele se traduz no relato dos imprevistos, tanto positivos quanto negativos, enfrentados ao longo do estudo, e as ações tomadas ou sugeridas. $O$ objetivo é detectar como isso afetou a performance, alavancando possíveis propostas para evitar a repetição de erros e melhorar o aproveitamento das oportunidades nos próximos projetos.

\section{Monitoramento e Controle}

Esse grupo acontece simultaneamente à execução. Ao longo da realização das atividades, deve-se conferir se está ocorrendo conforme o planejado e realizar as alterações necessárias nos casos de divergência. Tais mudanças devem ocorrer de forma integrada, observando o todo, não a situação isolada.

Quanto ao escopo, há dois processos:

- Validar escopo: verificar se o que está sendo entregue é o que foi definido no plano;

- Controlar escopo: fazer as modificações necessárias para alcançar todos os requisitos do escopo que não foram validados.

Já o cronograma possui apenas um processo:

- Controlar cronograma: averiguar os prazos e fazer as devidas alterações para manter o término pontual do projeto. 


\section{Encerramento}

Nesse grupo há apenas um processo: entregar o produto e finalizar o projeto. No meio empresarial estão incluídos, dentre outros fatores, encerramento de contratos, devolução de produtos alugados, realização de pagamentos, avaliação do projeto e do produto. Como o presente trabalho está voltado e limitado aos aspectos diretamente relacionados à música, não abrangendo fatores externos ao estudo, o processo de encerrar o projeto se limita à realização da performance final, acrescida de possível avaliação do resultado.

\section{Modelo para aplicação}

Uma alternativa viável é a simplificação em três documentos, equivalentes às áreas aprofundadas nesta proposta, contendo as informações essenciais para o estudo:

- Integração: estabelece o contexto e as condições do estudo e da performance, indicando, por exemplo, a justificativa do estudo, da performance e da escolha da obra; os objetivos; a performance almejada; as exigências da obra; as considerações e condições; a forma de avaliação; o ciclo de vida; o que é sucesso; as referências e os critérios para identificar requisitos; as circunstâncias fora do controle do músico; os hábitos; os exercícios; as técnicas e o conjunto de anotações/registros.

- Escopo: descreve o que será feito (EAP - Estrutura Analítica de Projeto, ou seja, organograma com os itens de estudo e seus requisitos).

- Cronograma: fornece graficamente a distribuição das tarefas no tempo, contendo lista de atividades com sua sequência lógica de precedência e quando realizá-las.

Para facilitar a aplicação, transformamos as informações necessárias de cada processo do fluxo em perguntas para que o instrumentista responda, frisando que podem ser retiradas ou acrescentadas questões de acordo com as particularidades de cada projeto. A maior parte se refere à integração, portanto, as perguntas e respostas podem ser consideradas como o próprio documento de integração. As demais apontam diretamente para a elaboração dos outros dois documentos, escopo e cronograma, que devem estar totalmente conectados ao primeiro.

1. Iniciação: Qual música? Que tipo de evento? Instrumentação? Data e local? Ensaios? Como quero a performance? Quem está envolvido?

2. Planejamento:

a. Qual a referência para definir os itens? O que é necessário ou exigido? Por que e para que essas necessidades? O que devo estudar (EAP)? O que é cada item? 
b. Como vou escolher as atividades? O que vou fazer se atrasar? Como vou ordenar? Quais as tarefas? Qual tarefa depende de qual? Qual a ordem? Quanto tempo vou gastar em cada atividade (cronograma)?

3. Execução: O que está ocorrendo de inesperado que devo observar nos próximos projetos?

4. Monitoramento e controle:

a. Estou tocando/foi estudado o que planejei? Como vou estudar o que faltou?

b. Está no prazo? Como vou manter a pontualidade?

5. Encerramento: Como foi a performance final? Alcancei o objetivo?

\section{Conclusão}

Através da revisão de literatura, percebemos que há uma enorme variedade de ferramentas sobre a preparação para a performance, muitas voltadas para a eficiência. A característica em comum entre elas é a preocupação com aspectos específicos, faltando investigações acerca do gerenciamento integrado de todos esses mecanismos ofertados pelos pesquisadores da música. Nosso intuito foi ofertar uma alternativa para a integração dos inúmeros assuntos tratados pelos autores de maneira a unificar as subdivisões feitas no estudo para aprofundá-lo.

Fundamentar na área administrativa empresarial se mostrou pertinente pela proximidade de objetivos: eficiência e autonomia por meio da gestão integrada do todo. Sendo assim, escolhemos o Guia PMBOK®, pois está entre os principais materiais da profissão de gerenciamento de projetos, que se assemelha à preparação para a performance por ambos serem esforços temporários com um objetivo final. Dessa forma, foi possível realizar uma proposta baseada na tradução das práticas empresariais para a música.

Até o momento, a pesquisa aponta, em teoria, que os principais benefícios são a assertividade na escolha das ferramentas, levando à eficiência das atividades, e a capacidade de estruturar e realizar o estudo de maneira autônoma através da clareza dos aspectos que devem ser estudados, mas sem descartar o suporte de um professor nos momentos de dúvidas e dificuldades. A proposição está alicerçada na integração para conectar o escopo e o cronograma aos objetivos estabelecidos e aos contextos em que o estudo se insere. Entretanto a pesquisa está em andamento e, provavelmente, muitos ajustes serão necessários através de sua futura aplicação prática e consequente análise. 


\section{REFERÊNCIAS}

ALVES, A. S.; MOREIRA, A. L. Análise musical de Regard de l'Onction terrible, de Olivier Messiaen: contexto, simbologia, forma e performance. Opus, v. 23, n. 1, p. 9-34, 2017. ISSN 15177017. Disponível em: https://www.anppom.com.br/revista/index.php/opus/ article/view/432. Acesso em: 21 set. 2020.

ALVES, R.; NODA, L.; CESETTI, D. Estratégias de estudo aplicadas na construção da performance de seis Études Op.33 de Karol Szymanowski. Vórtex, Curitiba, v. 7, n. 3, p. 1-32, 2019. ISSN 2317-9937. Disponível em: http://vortex.unespar.edu.br/alves_noda_ cesetti_v7_n3.pdf. Acesso em: 24 set. 2020.

ARAÚJO, G. A. F. D. Concerto para Violoncelo e Orquestra (1966/67) de José Guerra Vicente: aspectos históricos e análise técnica-interpretativa. 2016. 233 p. Dissertação (Mestrado em Música) - Universidade Federal de Minas Gerais, Belo Horizonte, 2016. Disponível em: https://sucupira.capes.gov.br/sucupira/public/consultas/coleta/ trabalhoConclusao/viewTrabalhoConclusao.jsf?popup=true\&id_trabalho $=4058542$. Acesso em: 10 nov. 2020.

AUTONOMIA. In: DICIO - Dicionário Online de Português. Porto: 7Graus, 2020. Disponível em: https://www.dicio.com.br/autonomia/. Acesso em: 27 jul. 2020.

BARROS, L. C. A pesquisa empírica sobre o planejamento da execução instrumental: uma reflexão crítica do sujeito de um estudo de caso. 2008. 265 p. Tese (Doutorado em Música) - Universidade Federral do Rio Grande do Sul, Porto Alegre, 2008. Disponível em: https://lume.ufrgs.br/handle/10183/13245. Acesso em: 6 nov. 2020.

BARROS, L. C.; CARVALHO, A. R.; BORGES, D. The "Artistic Image" Concept Applied to a Fugue at the Early Stage of Piano Practice: An Observational Study. Opus, v. 23, n. 3, p. 9-22, 2017. ISSN 15177017. Disponível em: https://www.anppom.com.br/revista/index. php/opus/article/view/opus2017c2301/458. Acesso em: 15 set. 2020.

BOGO, D. Aplicação de conceitos da psicologia cognitiva na construção de automatismos na leitura musical. Música Hodie, v. 16, n. 1, 2016. ISSN 15177017. Disponível em: https://revistas.ufg.br/musica/article/view/43114. Acesso em: 24 set. 2020.

BRAGAGNOLO, B.; GUIGUE, D. Análise da sonoridade em Ressonâncias de Marisa Rezende: uma abordagem a partir da performance. Opus, v. 23, n. 3, p. 222-253, 2017. ISSN 15177017. Disponível em: https://www.anppom.com.br/revista/index.php/opus/ article/view/opus2017c2310. Acesso em: 15 set. 2020. 
CARA JARA, M. A. Música contemporánea y estrategias de aprendizaje de una nueva pieza musical en la clase de piano. Música Hodie, v. 19, 2019. ISSN 15177017. Disponível em: https://revistas.ufg.br/musica/article/view/52532. Acesso em: 23 set. 2020.

CAREGNATO, C. Memorização, Percepção Musical e Cognição - Oito questionamentos do dia-a-dia. Vórtex, Curitiba, v. 5, n. 3, p. 1-19, 2017. ISSN 2317-9937. Disponível em: http://vortex.unespar.edu.br/caregnato_v5_n3.pdf. Acesso em: 25 set. 2020.

CARVALHO, C. S. Elementos da performance musical (EPM) na preparação de recitais de grupos de flautas doce. 2016. 46 f. Dissertação (Mestrado em Música) Universidade Federal de Goiás, Goiânia, 2016. Disponível em: https://sucupira.capes. gov.br/sucupira/public/consultas/coleta/trabalhoConclusao/viewTrabalhoConclusao. jsf?popup=true\&id_trabalho=3638200. Acesso em: 11 nov. 2020.

CECONELLO, M. Excerto orquestral para violino do poema sinfônico Don Juan Op. 20 de Richard Strauss: um estudo técnico-interpretativo. 2013. 131 f. Dissertação (Mestrado em Música) - Universidade Federal de Minas Gerais, Belo Horizonte, 2013. Disponível em: https://sucupira.capes.gov.br/sucupira/public/consultas/coleta/ trabalhoConclusao/viewTrabalhoConclusao.jsf?popup=truefid_trabalho=92010. Acesso em: 10 nov. 2020.

CHAFFIN, R.; IMREH, G. A Comparison of Practice and Self-Report as Sources of Information About the Goals of Expert Practice. Psychology of Music, New Jersey, v. 29, p. 39-69, 2001. Disponível em: https://www.researchgate.net/ publication/247733317_A_Comparison_of_Practice_and_Self-Report_as_Sources_ of_Information_About_the_Goals_of_Expert_Practice. Acesso em: 11 nov. 2020.

COSTA, M. A. Aprendizagem e transferência de habilidades motoras no ensino de piano funcional em grupo. Orfeu, v. 3, n. 1, p. 36-53, 2018. ISSN 25255304. Disponível em: https://www.revistas.udesc.br/index.php/orfeu/article/ view/1059652525530403012018036. Acesso em: 13 out. 2020.

COSTA, M. A.; HARTMANN, E. Estratégias interpretativas nos oito primeiros compassos da Sonata op. 2 no 1 para piano de Beethoven - uma análise comparativa de treze gravações de diferentes épocas. Opus, v. 24, n. 1, p. 50-77, 2018. ISSN 15177017. Disponível em: https://www.anppom.com.br/revista/index.php/opus/article/view/ opus2018a2403. Acesso em: 15 set. 2020.

CREMASCHI, A. M. The effect of a practice checklist on practice strategies, practice self-regulation and achievement of collegiate music majors enrolled in a beginning class piano course. Research Studies in Music Education, v. 34, n. 2, p. 223-233, 2012. Disponível em: https://journals.sagepub.com/doi/10.1177/1321103X12464743. Acesso em: 11 nov. 2020. 
DANJAS, K. Canção e Dansa para Contrabaixo e Piano de Radamés Gnattali: estudo de aspectos técnico-interpretativos. 2008. 67 f. Dissertação (Mestrado em Música) Universidade Federal de Minas Gerais, Belo Horizonte, 2008. Disponível em: http://hdl. handle.net/1843/GMMA-7XXLNN. Acesso em: 10 nov. 2020.

DELVIZIO, C. M. Os 12 Estudos para violão de Francisco Mignone: um estudo de caso sobre a solução de problemas técnicos violonísticos. 2019. 324 p. Tese (Doutorado em Música) - Universidade de São Paulo, São Paulo, 2019. Disponível em: https:// sucupira.capes.gov.br/sucupira/public/consultas/coleta/trabalhoConclusao/ viewTrabalhoConclusao.jsf?popup=true\&id_trabalho=7843567. Acesso em: 10 nov. 2020.

DEWEY, J. How we think. Nova York: D. C. Heath \& Co., 1910a.

The influence of Darwin on philosophy. [S. l.]: Henry Holt and Company, 1910b.

Democracy and education: an introduction to the philosophy of education. [S. l.]: Duke Classics, 1916. Edição Kindle. ISBN 978-1-62011-434-6.

Reconstruction in philosophy. Nova York: Henry Holt and Company, 1920.

Experience and education. Noa York: Simon \& Schuster, 1938.

DRAYTON, J. M. A theoretical model for practicing. 2013. 278 p. Tese (Degree of Doctor of Musical Arts) - University of Miami, Coral Gables, 2013. Disponível em: https:// scholarship.miami.edu/discovery/fulldisplay/alma991031447308602976/01UOML_ INST:ResearchRepository. Acesso em: 11 nov. 2020.

ERICSSON, K. A.; KRAMPE, R. T.; TESCH-ROMER, C. The Role of Deliberate Practice in the Acquisition of Expert Performance. Psychological Review, v. 100, n. 3, p. 363-406, 1993. Disponível em: https://graphics8.nytimes.com/images/blogs/freakonomics/pdf/ DeliberatePractice(PsychologicalReview).pdf. Acesso em: 21 out. 2020.

FAGUNDES, F. M. L.; RIBEIRO, G. M. A autonomia no Teatro Musical: as percepções dos participantes sob a perspectiva da Teoria da Autodeterminação. Música Hodie, v. 16, n. 1, 2016. ISSN 15177017. Disponível em: https://revistas.ufg.br/musica/article/ view/42981. Acesso em: 24 set. 2020.

FARIAS BUJES, P. Análise e aplicações do método Milanov para violino. Música Hodie, v. 16, n. 2, 2017. ISSN 2317-6776. Disponível em: https://revistas.ufg.br/musica/article/ view/45248. Acesso em: 24 set. 2020. 
FIAMINGHI, L. H.; MÜLLER, R. Ambiguidade métrica no Presto da Sonata para violino solo BWV 1001 de J. S. Bach: apontamentos para uma performance historicamente informada. Opus, v. 23, n. 2, p. 179-196, 2017. ISSN 15177017. Disponível em: https:// www.anppom.com.br/revista/index.php/opus/article/view/484. Acesso em: 15 set. 2020.

FRAGA, V. D. S. Estudo interpretativo sobre a fantasia sul américa para clarineta solo de Cláudio Santoro. 2008. 123 f. Dissertação (Mestrado em Excução Musical - Clarineta) - Universidade Federal da Bahia, Salvador, 2008. Disponível em: http://repositorio. ufba.br/ri/handle/ri/5625. Acesso em: 10 nov. 2020.

FREIRE, R. D. Como será que eu afino? A relação entre sistemas de afinação e parâmetros de afinação na performance musical. Música Hodie, v. 16, n. 2, 2017. ISSN 2317-6776. Disponível em: https://revistas.ufg.br/musica/article/view/45333. Acesso em: 24 set. 2020 .

GARCIA, P. A. J. Primeira Sonata-fantasia, désespérance, para violino e piano de Heitor Villa-Lobos: estratégias de estudo para violinista. 2015. 68 f. Dissertação (Mestrado em Música) - Universidade Federal do Rio Grande do Sul, Porto Alegre, 2015. Disponível em: https://sucupira.capes.gov.br/sucupira/public/consultas/coleta/ trabalhoConclusao/viewTrabalhoConclusao.jsf?popup=true\&id_trabalho=3008710. Acesso em: 11 nov. 2020.

GLASER, S. R. Processos de ensino e aprendizagem da performance pianística: um ensaio sob a perspectiva do princípio de continuidade de John Dewey. Revista da Abem, v. 26, n. 41, p. 98-114, 2018. Disponível em: http://www.abemeducacaomusical. com.br/revistas/revistaabem/index.php/revistaabem/article/view/788. Acesso em: 11 nov. 2020.

GOMES, L. F. Na Baixa do Sapateiro (Bahia) de Ary Barroso na interpretação de John Coltrane: a utilização da composição como veículo para a improvisação no jazz modal. Orfeu, v. 1, n. 2 (2016), p. 44-59, 2017. ISSN 2525-5304. Disponível em: https:// www.revistas.udesc.br/index.php/orfeu/article/view/1059652525530401022016044. Acesso em: 14 out. 2020.

HALLAM, S. et al. The development of practising strategies in young people. Psychology of Music, v. 4, n. 5, p. 652-680, 2012. Disponível em: https://journals. sagepub.com/doi/10.1177/0305735612443868. Acesso em: 11 nov. 2020.

HALLAM, S.; CREECH, A.; VARVARIGOU, M. Are there differences in practicing and motivation between beginners playing different musical instruments? Orfeu, v. 3, n. 1, p. 54-84, 2018. ISSN 2525-5304. Disponível em: https://www.revistas.udesc.br/index. php/orfeu/article/view/1059652525530403012018054. Acesso em: 13 out. 2020. 
HAMOND, L.; ADDESSI, A. R. Perspectivas de alunos de Bacharelado em Piano quanto ao uso do software MIROR- Impro para desenvolvimento de improvisação. Orfeu, v. 4, n. 2, p. 79-103, 2019. ISSN 2525-5304. Disponível em: https://www.revistas.udesc. br/index.php/orfeu/article/view/1059652525530404022019079. Acesso em: 13 out. 2020.

HODGSON, D.; CICMIL, S. Are projects real? The PMBOK and the legitimation of project management knowledge. In: HODGSON, D. C. S. Making Projects Critical. Basingstoke: Palgrave, 2006. Cap. 1.

KIMACHI, R. Cronograma de estudos diários para flautistas: otimizando o tempo de estudo. In: DALDEGAN, V.; D'ÁVILA, R. C. Pattapios: coletânea comemorativa aos 20 anos da Associação Brasileira de Flautistas. Curitiba: Antigoa Typographia; ABRAF, 2014. p. 219-227.

MACEDO, P. L. D. S. A preparação para performance de livre improvisação no contrabaixo. 2016. 86 f. Dissertação (Mestrado em Música) - Universidade Estadual Paulista Júlio de Mesquita Filho, São Paulo, 2016. Disponível em: https:// sucupira.capes.gov.br/sucupira/public/consultas/coleta/trabalhoConclusao/ viewTrabalhoConclusao.jsf?popup=truefid_trabalho=3693447. Acesso em: 10 nov. 2020.

MANTOVANI, M. R.; SANTOS, R. A. T. D. Categorias Psicossensoriais da prática pianística em diferentes níveis de expertise: perspectivas de deliberação. Opus, v. 24, n. 3, p. 26-54, 2018. ISSN 15177017. Disponível em: https://www.anppom.com.br/revista/ index.php/opus/article/view/opus2018c2402. Acesso em: 15 set. 2020.

MELLO, F. M. D. Preparação para performance de música de câmara com violão: o uso do corpo no repertório com técnicas estendidas. 2015. 93 f. Dissertação (Mestrado em Música) - Universidade Estadual Paulista Júlio de Mesquita Filho, São Paulo, 2015. Disponível em: https://sucupira.capes.gov.br/sucupira/public/consultas/coleta/ trabalhoConclusao/viewTrabalhoConclusao.jsf?popup=true\&id_trabalho=2857688. Acesso em: 10 nov. 2020.

MEZZADRI, D. Spider Log: criação de um sistema entrelaçado de estudo com representação visual de progresso. In: FESTIVAL INTERNACIONAL DE FLAUTISTAS, 14., São Paulo. Anais [...]. São Paulo: Associação Brasileira de Flautistas, 7 a 10 set. 2017. p. 23-29.

NUNES, M.; ALÍPIO, A. O processo de digitação ao violão para o Prelúdio BWV 997 de Johann Sebastian Bach. Música Hodie, v. 16, n. 2, 2017. ISSN 2317-6776. Disponível em: https://revistas.ufg.br/musica/article/view/45310. Acesso em: 24 set. 2020. 
OLIVEIRA, J. Z. D. Reflexões sobre a importância da prática deliberada para otimização da performance musical do clarinetista. 2019. 95 f. Dissertação (Mestrado Profissional em Música) - Universidade Federal da Bahia, Salvador, 2019. Disponível em: https:// sucupira.capes.gov.br/sucupira/public/consultas/coleta/trabalhoConclusao/ viewTrabalhoConclusao.jsf?popup=truefid_trabalho=8041016. Acesso em: 11 nov. 2020.

PALOPOLI, C. O. Estudo comparativo entre edições da Sequenza I para flauta solo de Luciano Berio: subsídios para compreensão e interpretação da obra. 2013. 182 f. Dissertação (Mestrado em Música) - Universidade de São Paulo, São Paulo, 2013. Disponível em: https://sucupira.capes.gov.br/sucupira/public/consultas/coleta/ trabalhoConclusao/viewTrabalhoConclusao.jsf?popup=truefid_trabalho $=617803$. Acesso em: 10 nov. 2020.

PICCOLI, L. F. Aprendizagem musical e prática individual: um estudo de caso e o esboço de um modelo próprio de engajamento pessoal. 2016. 95 f. Dissertação (Mestrado em Música) - Universidade Federal do Rio Grande do Norte, Natal, 2016. Disponível em: https://sucupira.capes.gov.br/sucupira/public/consultas/coleta/ trabalhoConclusao/viewTrabalhoConclusao.jsf?popup=true\&id_trabalho=5067558. Acesso em: 11 nov. 2020.

PILATTI, G. Improviso no 3 para Flauta Solo de Camargo Guarnieri: desconstrução da obra a partir dos elementos rítmicos e melódicos como processo auxiliar na performance musical. 2008. 141 f. Dissertação (Mestrado em Execução Musical) Universidade Federal da Bahia, Salvador, 2008. Disponível em: https://repositorio.ufba. $\mathrm{br} / \mathrm{ri} / \mathrm{bitstream} / \mathrm{ri} / 9111 / 1 /$ Dissertacao\%20Giampiero\%20Pilatti.pdf. Acesso em: 10 nov. 2020.

PMBOK® Guide 6a Edição Explicado com Ricardo Vargas! [S. l.: s. n.], 2017. 1 vídeo (49 min). Publicado pelo canal Ricardo Vargas. Disponível em: https://www.youtube.com/ watch?v=rvDnS_wWwJs. Acesso em: 11 nov. 2020.

PMI, P. M. I. Um guia do conhecimento em gerenciamento de projetos (Guia PMBOK®). 6. ed. Newtown Square: [s. n.], 2017. ISBN 9781628253924.

The standard for organizational project management (OPM). Newtown Square: [s. n.], 2018. ISBN 9781628255560.

PONTES, L. Sugestões para a preparação de excertos orquestrais do romantismo para viola. Música Hodie, v. 16, n. 2, 2017. ISSN 2317-6776. Disponível em: https://revistas. ufg.br/musica/article/view/45273. Acesso em: 24 set. 2020. 
PÓVOAS, M. B. C. Desempenho pianístico e organização do estudo através do Rodízio: um sistema de treinamento baseado na distribuição e variabilidade da prática. Opus, v. 23, n. 1, p. 187-204, 2017. ISSN 15177017. Disponível em: https://www.anppom.com.br/ revista/index.php/opus/article/view/440/412. Acesso em: 21 set. 2020.

QUINTERIO, L. Estratégias para a rotina de estudo do violonista: uma perspectiva baseada na aprendizagem autorregulada. 2017. 116 f. Dissertação (Mestrado em Música) - Escola de Comunicações e Artes, Universidade de São Paulo, São Paulo, 2017. Disponível em: https://teses.usp.br/teses/disponiveis/27/27158/tde-26022018105629/publico/Dissert_Leandro_corrigida_FINAL.pdf. Acesso em: 21 out. 2020.

RAY, S. Prática e didática da música de câmara. Orfeu, v. 4, n. 1, p. 151-165, 11 set. 2019. ISSN 2525-5304. Disponível em: https://www.revistas.udesc.br/index.php/orfeu/ article/view/1059652525530404012019151. Acesso em: 13 out. 2020.

RODRIGUES, J. M. B. Audições orquestrais para flauta no Brasil: um estudo sobre estratégias de preparação. 2015. 75 f. Dissertação (Mestrado em Música) Universidade Federal de Minas Gerais, Belo Horizonte, 2015. Disponível em: https:// sucupira.capes.gov.br/sucupira/public/consultas/coleta/trabalhoConclusao/ viewTrabalhoConclusao.jsf?popup=truefid_trabalho=2596110. Acesso em: 11 nov. 2020.

RODRIGUES, R.; SANTOS, R. A. T. D. Discernment of shades of sadness in Guarnieri's Ponteios. Per Musi, n. 38, 14, 2018. ISSN 2317-6377. Disponível em: https://periodicos. ufmg.br/index.php/permusi/article/view/5227. Acesso em: 10 set. 2020.

ROOIJ, S. W. V. Scaffolding Project-based learning with the project management body of knowledge (PMBOK). Computers \& Education, Elsevier, v. 52, p. 210-219, 2009.

ROSA, R. M.; BARREIRO, D. L. O processo de elaboração de uma concepção interpretativa de Tetragrammaton XIII, de Roberto Victorio: aguçamento da escuta em interação com a análise de gravações da obra. Vórtex, Curitiba, v. 7, n. 1, p. 1-35, 2019. ISSN 2317-9937. Disponível em: http://vortex.unespar.edu.br/rosa_barreiro_v7_ n1.pdf. Acesso em: 25 set. 2020.

RUBIO, M. C.; FALLEIROS, M.; FORNARI, J. La libre improvisación en la Escuelalibre de Música CIDDIC-UNICAMP. Propuesta metodológica para la adquisición de habilidades, capacidades y actitudes dentro del ensemble de saxofones. Vórtex, Curitiba, v. 7, n. 2, p. 1-18, 2019. ISSN 2317-9937. Disponível em: http://vortex.unespar.edu.br/rubio_ falleiros_fornari_v7_n2.pdf. Acesso em: 24 set. 2020. 
SBAFFI, E. Concerto per Violoncello Obligato con Violini e Basso Dell Sigre Antonio Pollicarppi: Authorship, Analysis and Interpretation of the DKmu 7501.2432

Manuscript. Per Musi, n. 36, 5, 2018. ISSN 2317-6377. Disponível em: https://periodicos. ufmg.br/index.php/permusi/article/view/5189. Acesso em: 11 set. 2020.

SILVA, L. P. D. C. E.; PÁSCOA, L. V. B. Uma abordagem iconográfica musical da obra O Violeiro de Almeida Júnior. Música Hodie, v. 18, n. 2, p. 245-253, 2018. ISSN 15177017. Disponível em: https://revistas.ufg.br/musica/article/view/51675. Acesso em: 23 set. 2020.

SILVA, R. C. L. Ensino e aprendizagem de improvisação em um curso superior de Música. 2013. 193 f. Dissertação (Mestrado em Música) - Universidade Federal de Minas Gerais, Belo Horizonte, 2013. Disponível em: https://sucupira.capes.gov. br/sucupira/public/consultas/coleta/trabalhoConclusao/viewTrabalhoConclusao. jsf?popup=true\&id_trabalho=151955. Acesso em: 10 nov. 2020.

SINICO, A.; GERLING, C. C. Prélude à l'après-midi d'un faune by Claude Debussy. Per Musi, n. 37, 2018. ISSN 2317-6377. Disponível em: https://periodicos.ufmg.br/index. php/permusi/article/view/5280. Acesso em: 10 set. 2020.

SOARES, N. N.; GERLING, C. C. Sonata para piano n. 1 de Francisco Mignone: uma comparação de performances. Orfeu, v. 3, n. 2, p. 261-294, 2018. ISSN 25255304. Disponível em: https://www.revistas.udesc.br/index.php/orfeu/article/ view/1059652525530403022018261. Acesso em: 13 out. 2020.

SOLLERO, P. A. O cuidado de si e a preparação para improvisação musical livre. Orfeu, v. 1, n. 2 (2016), p. 79-95, 2017. ISSN 2525-5304. Disponível em: https://www.revistas. udesc.br/index.php/orfeu/article/view/1059652525530401022016079. Acesso em: 14 out. 2020.

SOUZA, I. V. L. D. O Preludio n. 1 para piano de Eunice Katunda "à maneira popular". Orfeu, 2017, v. 2, n. 1, p. 226-242. ISSN 2525-5304. Disponível em: https://www. revistas.udesc.br/index.php/orfeu/article/view/1059652525530402012017226. Acesso em: 14 out. 2020.

SOUZA, M. R. D. Guerra-Peixe's Symphony No. 2 Brasília (Part 2). Per Musi, n. 38, 2018. ISSN 2317-6377. Disponível em: https://periodicos.ufmg.br/index.php/permusi/article/ view/5243. Acesso em: 10 set. 2020.

VALENTE, K. T.; PRESGRAVE, F. S.; MELLO FILHO, S. F. D. Abordagens de estudo e performance da obra Responsório ao Vento para violoncelo solo de Silvio Ferraz. Música Hodie, v. 16, n. 2, 2017. ISSN 15177017. Disponível em: https://revistas.ufg.br/ musica/article/view/45213. Acesso em: 24 set. 2020. 
VARGAS, R. V. A New Approach to PMBOK® Guide 2000. PMI Global Congress North America. Neshville, USA: [s. n.], 2001. p. 215-226.

Fluxo de Processos do PMBOK Guide®. 6. ed. [S. l.: s. n.], 2017. Disponível em: http://rvarg.as/pmbok6. Acesso em: 12 nov. 2020.

VELOSO, F. D. D.; ARAÚJO, R. C. D. A aprendizagem da performance musical na visão sociocognitiva: aportes da Abordagem Multidimensional da Autorregulação. Opus, v. 25, n. 3, p. 133-157, 2019. ISSN 15177017. Disponível em: https://www.anppom.com.br/ revista/index.php/opus/article/view/opus2019c2507. Acesso em: 14 set. 2020.

VETROMILLA, C.; GABRIEL, F. Uma análise da prática diária de Pacho Flores: aquecimentos e estudos técnicos para trompete. Orfeu, v. 4, n. 2, p. 224-241, 2019. ISSN 2525-5304. Disponível em: https://www.revistas.udesc.br/index.php/orfeu/ article/view/1059652525530404022019224. Acesso em: 13 out. 2020.

ZIMBRES, P. Pianistas ou Pianeiros: duas interpretações do tango Fon Fon de Ernesto Nazareth. Orfeu, v. 4, n. 2, p. 169-189, 2019. ISSN 2525-5304. Disponível em: https:// www.revistas.udesc.br/index.php/orfeu/article/view/1059652525530404022019169. Acesso em: 13 out. 2020.

ZWIKAEL, O. The relative importance od the PMBOK Guide's nine knowledge areas during project planning. Project Management Journal, v. 40, n. 4, p. 94-103, 2009. 